NASA/TM-2000-210068

Fuzzy Current-Mode Control and Stability Analysis

George Kopasakis

Glenn Research Center, Cleveland, Ohio 
Since its founding, NASA has been dedicated to the advancement of aeronautics and space science. The NASA Scientific and Technical Information (STI) Program Office plays a key part in helping NASA maintain this important role.

The NASA STI Program Office is operated by Langley Research Center, the Lead Center for NASA's scientific and technical information. The NASA STI Program Office provides access to the NASA STI Database, the largest collection of aeronautical and space science STI in the world. The Program Office is also NASA's institutional mechanism for disseminating the results of its research and development activities. These results are published by NASA in the NASA STI Report Series, which includes the following report types:

- TECHNICAL PUBLICATION. Reports of completed research or a major significant phase of research that present the results of NASA programs and include extensive data or theoretical analysis. Includes compilations of significant scientific and technical data and information deemed to be of continuing reference value. NASA's counterpart of peerreviewed formal professional papers but has less stringent limitations on manuscript length and extent of graphic presentations.

- TECHNICAL MEMORANDUM. Scientific and technical findings that are preliminary or of specialized interest, e.g., quick release reports, working papers, and bibliographies that contain minimal annotation. Does not contain extensive analysis.

- CONTRACTOR REPORT. Scientific and technical findings by NASA-sponsored contractors and grantees.
- CONFERENCE PUBLICATION. Collected papers from scientific and technical conferences, symposia, seminars, or other meetings sponsored or cosponsored by NASA.

- SPECIAL PUBLICATION. Scientific, technical, or historical information from NASA programs, projects, and missions, often concerned with subjects having substantial public interest.

- TECHNICAL TRANSLATION. Englishlanguage translations of foreign scientific and technical material pertinent to NASA's mission.

Specialized services that complement the STI Program Office's diverse offerings include creating custom thesauri, building customized data bases, organizing and publishing research results ... even providing videos.

For more information about the NASA STI Program Office, see the following:

- Access the NASA STI Program Home Page at http://www.sti.nasa.gov

- E-mail your question via the Internet to help@sti.nasa.gov

- Fax your question to the NASA Access Help Desk at (301) 621-0134

- Telephone the NASA Access Help Desk at (301) 621-0390

- Write to: NASA Access Help Desk NASA Center for AeroSpace Information 7121 Standard Drive Hanover, MD 21076 
NASA/TM-2000-210068

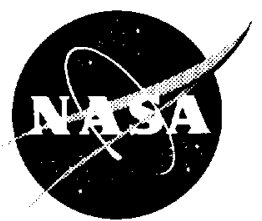

\section{Fuzzy Current-Mode Control and Stability Analysis}

George Kopasakis

Glenn Research Center, Cleveland, Ohio

Prepared for the

35th Intersociety Energy Conversion Engineering Conference sponsored by the American Institute of Aeronautics and Astronautics Las Vegas, Nevada, July 24-28, 2000

National Aeronautics and

Space Administration

Glenn Research Center 
Available from

NASA Center for Aerospace Information

7121 Standard Drive

Hanover, MD 21076

Price Code: A03
National Technical Information Service 5285 Port Royal Road Springfield, VA 22100 Price Code: $\mathrm{A} 03$ 


\title{
FUZZY CURRENT-MODE CONTROL AND STABILITY ANALYSIS
}

\author{
George Kopasakis \\ National Aeronautics and Space Administration \\ Glenn Research Center \\ Cleveland. Ohio 44135
}

\begin{abstract}
$\underline{\text { Abstract }}$
In this paper a current-mode control (CMC) methodology is developed for a buck converter by using a fuzzy logic controller. Conventional CMC methodologies are based on lead-lag compensation with voltage and inductor current feedback. In this paper the converter lead-lag compensation will be substituted with a fuzzy controller. A small-signal model of the fuzzy controller will also be developed in order to examine the stability properties of this buck converter control system. The paper develops an analytical approach, introducing fuzzy control into the area of $\mathrm{CMC}$.
\end{abstract}

\section{Introduction}

Fuzzy control has emerged as one of the most active and promising control areas. especially because it can control highly nonlinear, time-variant, and ill-defined systems. The work of Mamdani and his colleagues on fuzzy control ${ }^{1-2}$ was motivated by Zadeh's work on the theory of fuzzy sets, ${ }^{3-4}$ and its application to linguistics and systems analysis. Layne later modified work by Procyk, Mamdani. and others on the linguistic selforganizing controller to what it is now, Fuzzy Model Reference Learning Control (FMRLC). ${ }^{5}$

Existing CMC techniques ${ }^{6-8}$ primarily employ analog lead-lag compensation to shape the closed-loop gain of the converter (magnitude and phase) in order to achieve certain design criteria, such as stability margins, low output impedance. low audio susceptibility, and response time characteristics like overshoot, settling time, and zero steady-state error. In this paper fuzzy control will be used, instead, to control a $6-\mathrm{kW}$ converter with constant-power or negative-resistance loading. The rest of the design procedure, such as the insertion of the control-stabilizing ramp signal. the inductor current feedback and the design of the slopes of the feedback signals, will follow the same procedures as the traditional CMC design. The existing CMC methodology of fers a comprehensive and methodical approach to meeting design criteria in both the frequency and time domains. The approach introduced here offers a design alternative for converter control by incorporating modern nonlinear control design approaches, such as fuzzy control, while still being able to use powerful frequency domain analysis techniques.

Initially, in this paper, the FMRLC approach will be employed to control the converter. Later the control law learned by using FMRLC will be employed using instead a conventional fuzzy controller to control the process. The FMRLC control technique could be used as the final control. However, because the FMRLC exhibits nonstationary nonlinearities, it is not amenable to smallsignal, frequency domain analysis. A small-signal model of the converter will be constructed initially to help understand how to develop a heuristic, inverse fuzzy model of the converter, which is needed to employ the FMRLC technique. Later the small-signal model of the converter will be used to help analyze the stability properties of the control system. Sinusoidal sweeps will be applied to the fuzzy controller to construct frequency domain responses by employing fast Fourier transforms (FFT"s). The small-signal transfer functions of the fuzzy controller will be constructed by using pole-zero approximation of the frequency responses.

\section{Converter Model}

\subsection{Large-Signal, Switch-Mode Model}

Figure 1 shows the model of a switch-mode. $6-\mathrm{kW}$ buck converter regulator. The power stage equations for the large-signal nonlinear model are

$$
\begin{gathered}
\frac{d i_{l}}{d t}=\frac{1}{L_{f}}\left(v_{g}-v_{o}\right) \\
\frac{d v_{c}}{d t}=\frac{i_{c}}{C_{f}} \\
\frac{d i_{c}}{d t}=\frac{1}{L_{c}}\left(v_{o}-i_{c} R_{c}-v_{c}\right) \\
i_{o}=i_{l}-i_{c} \\
v_{o}=P_{o} / i_{o}
\end{gathered}
$$




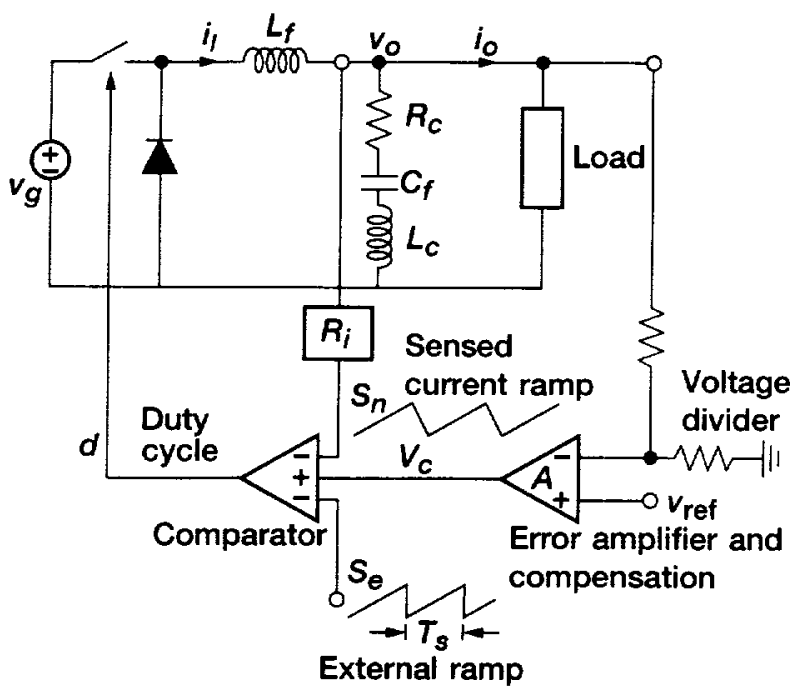

Figure 1.-Switch-mode, 6-kW buck converter regulator.

where $R_{c}$ and $L_{c}$ are the filter capacitor effective series resistance and inductance, respectively, and $P_{o}$ is the load power. The nonlinear switch-mode model has two operating modes per conducting cycle: mode 1 , when the switch is closed and Eqs. (1) to (5) are active; and mode 2, when the switch is open $\left(v_{g}=0\right)$ and the fly-back diode is conducting.

\subsection{Small-Signal, Power Stage Model in Continuous Conduction Mode}

Figure 2 shows the small-signal continuous conduction mode (CCM) perturbation model of the buck converter power stage. This model is derived from performing statespace average ${ }^{8}$ of the nonlinear switch-mode model above, to come up with the large-signal average model, and then perturbing this model to calculate the small-signal perturbation model:

$$
\begin{gathered}
\hat{i}_{l}=\frac{1}{s L_{f}}\left(V_{g} \hat{d}-D V_{o}-V_{o} \hat{d}\right) \\
\hat{v}_{o}=\left(I_{l} \hat{d}+D \hat{i_{l}}\right) Z(s) \\
Z(s)=\frac{R_{l}\left(C_{f} L_{c} s^{2}+R_{c} C_{f} s+1\right)}{C_{f} L_{c} s^{2}+R_{l} C_{f} s+1}, \text { for } R_{c}\left\langle\left\langle R_{l}\right.\right.
\end{gathered}
$$

Substituting Eq. (6) into Eq. (7) and after some simplifications:

$$
\frac{\hat{v}_{o}}{\hat{d}}=\frac{V_{g}-V_{o}}{D} \frac{P_{n}(s)}{P_{d}(s)}
$$

where

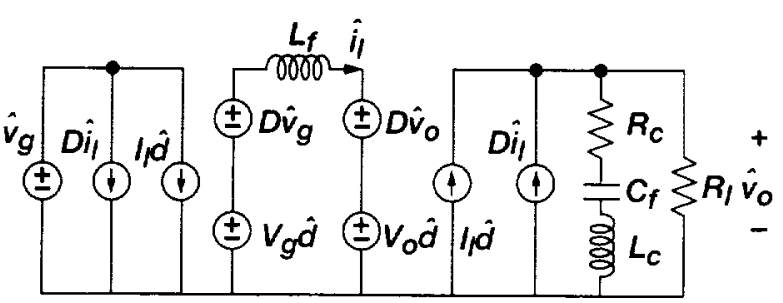

Figure 2.-Small-signal CCM perturbation model of buck converter power stage.

$$
\begin{gathered}
P_{n}(s)=\frac{L_{f} L_{c} C_{f} I_{l}}{A} s^{3}+\frac{L_{f} C_{f} l_{l} R_{c}}{A} s^{2}+\frac{L_{f} I_{l}}{A} s+1 \\
P_{d}(s)=\frac{L_{f} L_{c} C_{f}}{B} s^{3}+\frac{R_{l} L_{f} C_{f}}{B} s^{2}+\frac{L_{f}}{B} s+1
\end{gathered}
$$

$A=D\left(V_{g}-V_{o}\right), B=D^{2} R_{l}$, and $D$ is the duty cycle. Similarly, substituting Eq. (7) into Eq. (6) and after some simplifications:

$$
\frac{\hat{i}_{i}}{\hat{d}}=\frac{E}{B} \frac{C_{f} L_{c} s^{2}+\left[\left(V_{g}-V_{o}\right) R_{l} C_{f} / E\right] s+1}{P_{d}(s)}
$$

where $E=V_{g}-V_{o}-D I_{l}$ and $D, V_{g}, V_{o}$, and $I_{l}$, in Eqs. (6) to (10) represent average quantities over a conduction cycle of the duty cycle, input voltage, output voltage, and inductor current, respectively.

The corresponding lower case variables with the hat represent the perturbation quantities of these variables. Equations (9) and (10) represent the small-signal transfer functions of the duty cycle to the output voltage and the inductor current, respectively. Other transfer functions necessary for a complete CCM model of the converter power stage or the discontinuous conduction mode (DCM) model will not be derived here as this is beyond the scope of this paper. Figures 3 and 4 show frequency responses of Eqs. (9) and (10), respectively, at $100 \%$ constant-power load $\left(-R_{l}\right)$ with $V_{g}=160$ volts, $V_{o}=120$ volts, $L_{f}=80 \mu \mathrm{H}$, $C_{f}=320 \mu \mathrm{F}, R_{c}=20 \mathrm{~m} \Omega, L_{c}=0.5 \mu \mathrm{H}$.

Figure 5 shows the small-signal, control-to-output model $^{8}$ in CCM. From Fig. 5 with $G_{v}=\hat{v}_{o} / \hat{d}$ and $G_{i}=\hat{i}_{l} / \hat{d}$,

$$
\begin{gathered}
\hat{d}=F_{m}\left[K_{r} \hat{v}_{o}+F_{c} \hat{v}_{c}-R_{i} H_{e}(s) G_{i}(s) \hat{d}\right] \\
\hat{v}_{o}=G_{v} \hat{d}
\end{gathered}
$$

Solving for $\hat{d}$ in Eq. (11) and substituting into Eq. (12) to solve for $\hat{v}_{o} / \hat{v}_{c}$ gives

$$
\frac{\hat{v}_{o}}{\hat{v}_{c}}=\frac{F_{c} F_{m} G_{v}(s)}{1+F_{m} R_{i} H_{e}(s) G_{i}(s)-F_{m} K_{r} G_{v}(s)}
$$



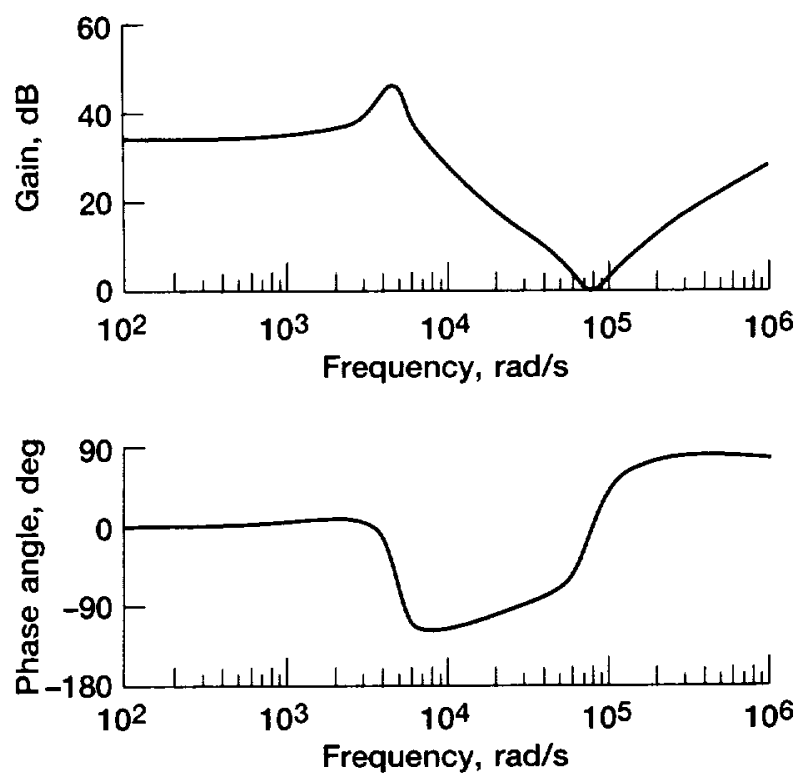

Figure 3.-Frequency response of $\hat{v}_{o} / \hat{d}$.
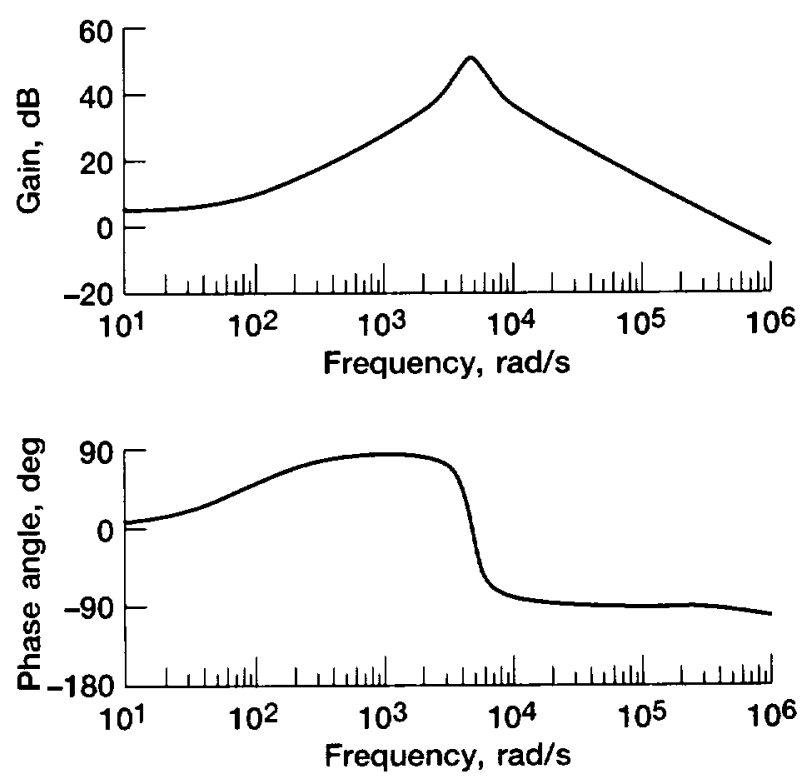

Figure 4.-Frequency response of $\hat{i}_{/} / \hat{d}$.

where, for the buck converter case, ${ }^{7}$

$$
\begin{gathered}
H_{e}=1+\frac{s}{\omega_{n} Q_{z}}+\frac{s^{2}}{\omega_{n}^{2}}, K_{r}=\frac{T_{s} R_{i}}{2 L_{f}}, Q_{z}=\frac{-2}{\pi}, \\
\omega_{n}=\frac{\pi}{T_{s}}, F_{m}=\frac{1}{\left(S_{n}+S_{e}\right) T_{s}}, F_{c}=1
\end{gathered}
$$

$T_{s}$ is the conduction period in seconds, $S_{n}$ is the rising slope of the inductor current feedback, and $S_{e}$ is the slope of the stabilizing sawtooth signal. Figure 6 shows a frequency response of Eq. (13) at $100 \%$ load with a switching

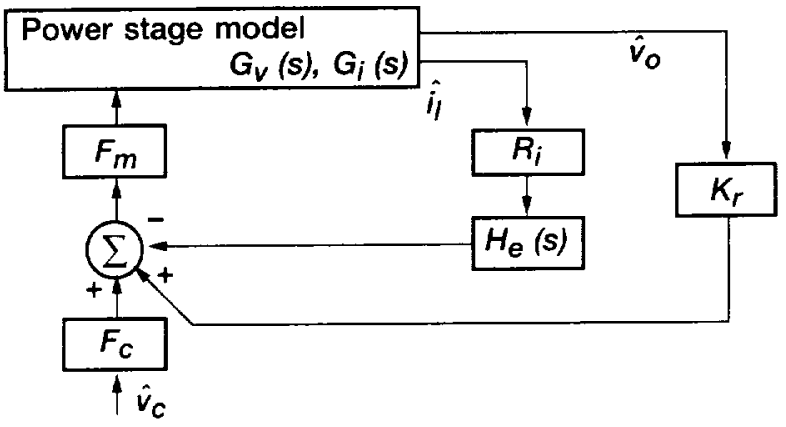

Figure 5.-Small-signal, control-to-output model in $\mathrm{CCM}$.
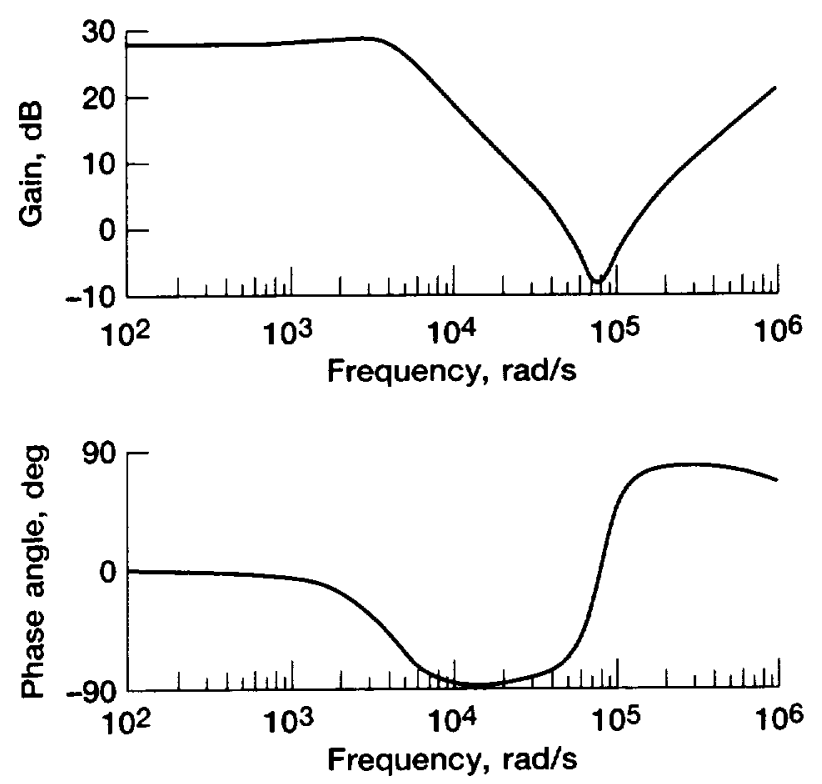

Figure 6.-Frequency response of $\hat{v}_{o} / \hat{v}_{c}$.

frequency of $40 \mathrm{kHz}, R_{i}=0.02 . S_{e}=80000$. and $S_{n}=11000$.

\section{Fuzzy Current-Mode Control}

\subsection{FMRLC Current-Mode Control}

Figure 7 shows the basic FMRLC structure ${ }^{5}$ with the addition of a pole at the origin placed at the output of the fuzzy controller. The proposed fuzzy controller will be replacing the traditional lead-lag compensation. The gains of the FMRLC controller are tuned on the basis of information gained from an open-loop step response of the process and guidelines generated by the author ${ }^{9-10}$ For each fuzzy input 11 evenly distributed triangular membership functions are chosen, resulting in 121 rules. Each membership function has a base width of 0.4 . For the FMRLC the inverse-model knowledge base of the process needs to be developed. This knowledge base does not necessarily need to exhibit high accuracy; however, it needs to exhibit the right output control directionality. The 


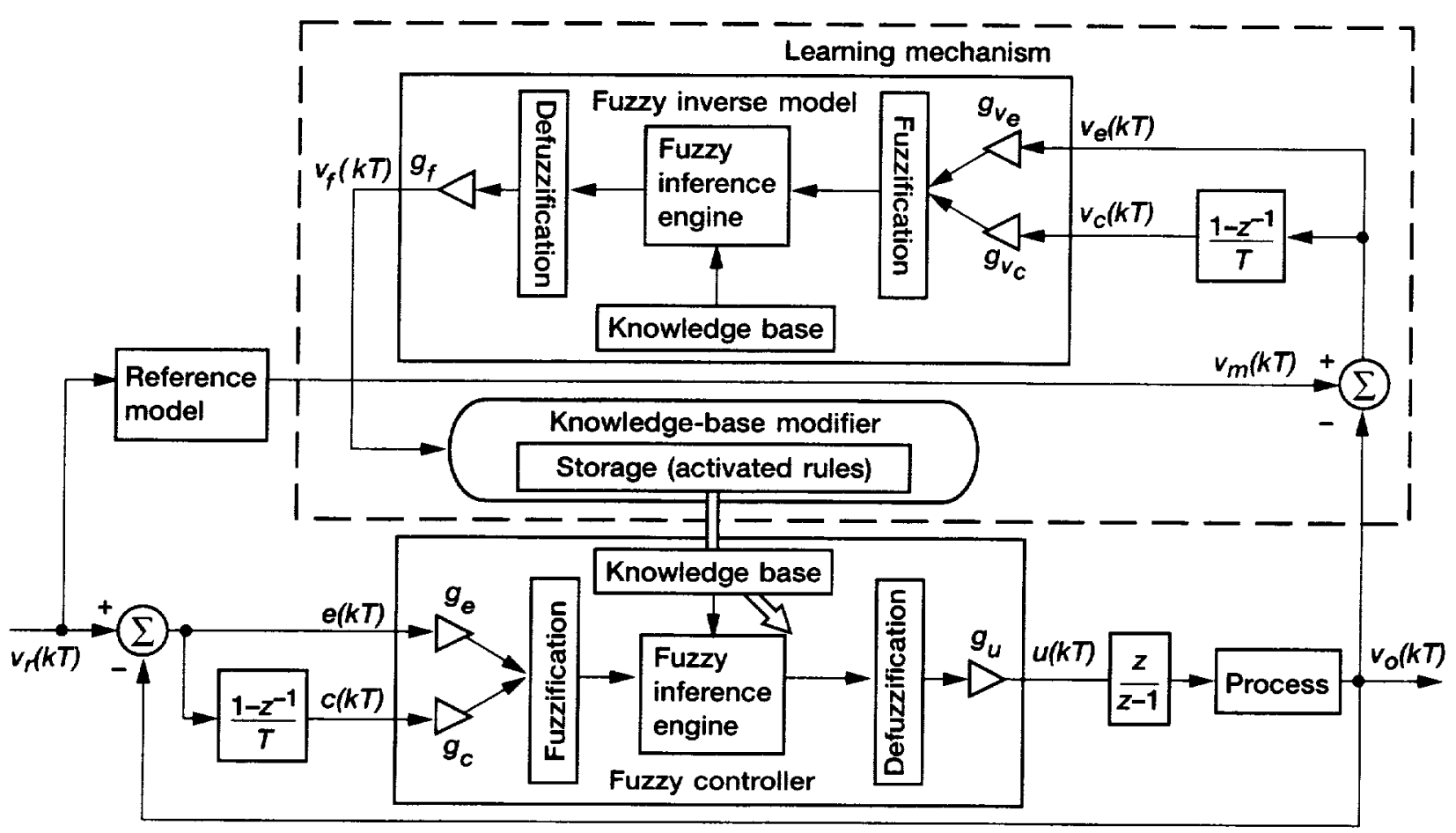

Figure 7.-FMRLC structure.

\begin{tabular}{|c|c|c|c|c|c|c|c|c|c|c|c|c|}
\hline \multirow{2}{*}{\multicolumn{2}{|c|}{$P_{i}^{j, k}$}} & \multicolumn{11}{|c|}{$V_{c}^{k}$} \\
\hline & & -5 & -4 & -3 & -2 & -1 & 0 & +1 & +2 & +3 & +4 & +5 \\
\hline \multirow{11}{*}{$V_{e}^{J}$} & -5 & -1.0 & -0.9 & -0.8 & -0.7 & -0.6 & -0.5 & -0.4 & -0.3 & -0.2 & -0.1 & $-千 00.0$ \\
\hline & -4 & -0.9 & -0.8 & -0.7 & -0.6 & -0.5 & -0.4 & -0.3 & -0.2 & -0.1 & $\mp 0.0$ & +0.0 \\
\hline & -3 & -0.8 & -0.7 & -0.6 & -0.5 & -0.4 & -0.3 & -0.2 & $-0.1-$ & 70.0 & +0.0 & +0.0 \\
\hline & -2 & -0.7 & -0.6 & -0.5 & -0.4 & -0.3 & -0.2 & -0.1 & -千0́.0 & +0.0 & +0.0 & +0.0 \\
\hline & -1 & $=0.6$ & $=0.5$ & $=-0.4$ & $=0.3$ & $=0.2$ & $=0.1$ & $-f 0.0$ & +0.0 & +0.0 & +0.0 & +0.0 \\
\hline & 0 & -0.0 & -0.0 & 0.0 & -0.0 & -0.0 & \pm 0.0 & +0.0 & \pm 0.0 & \pm 0.0 & +0.0 & ++0.0 \\
\hline & +1 & -0.0 & -0.0 & -0.0 & -0.0 & +0.0 & $\mp 0.1$ & +0.2 & +0.3 & +0.4 & +0.5 & +0.6 \\
\hline & +2 & -0.0 & -0.0 & -0.0 & +0.0 & $\mp 0.1$ & +0.2 & +0.3 & +0.4 & +0.5 & +0.6 & +0.7 \\
\hline & +3 & -0.0 & -0.0 & +0.0 & 70.1 & +0.2 & +0.3 & +0.4 & +0.5 & +0.6 & +0.7 & +0.8 \\
\hline & +4 & -0.0 & +0.0 & -千0́.1 & +0.2 & +0.3 & +0.4 & +0.5 & +0.6 & +0.7 & +0.8 & +0.9 \\
\hline & +5 & +0.2 & $\mp 0.1$ & +0.2 & +0.3 & +0.4 & +0.5 & +0.6 & +0.7 & +0.8 & +0.9 & +1.0 \\
\hline
\end{tabular}

Figure 8.-Inverse fuzzy model rule base, also showing zeroed-out elements to eliminate sensitivity to undamped inductor current response.

inputs to the FMRLC (Fig. 7) are the output voltage error and the output voltage error derivative.

The error derivative is proportional to the output voltage derivative $V_{o}$, where the derivative of $V_{o}$ is approximately proportional to the inductor current $I_{l}$, from Eq. (2) $V_{o} \cong V_{c}$, and Eq. (4) for $I_{o}$ is approximately constant over a conduction cycle. From the frequency response of $\hat{i}_{l} / \hat{d}$ (Fig. 4), it is evident that the response of the inductor current to the duty cycle is highly undamped. This result was expected, since very little damping was used in terms of the $R_{c}$ value chosen, purposely, to make the control design more challenging. Therefore, in constructing this knowledge base the elements associated with the error derivative that can cause a sign reversal of the control output variable are zeroed out (Fig. 8). Simulations, not shown here, showed that the time response of the closedloop system will stall out before the output voltage reaches its reference and that the output voltage will oscillate at that point if these elements of the fuzzy model have other than zero values.

Figure 9 shows the closed-loop step response of the FMRLC system. The reference model of the controller has been modified to automatically reset every time the output voltage recovers and starts moving toward the set point, in 

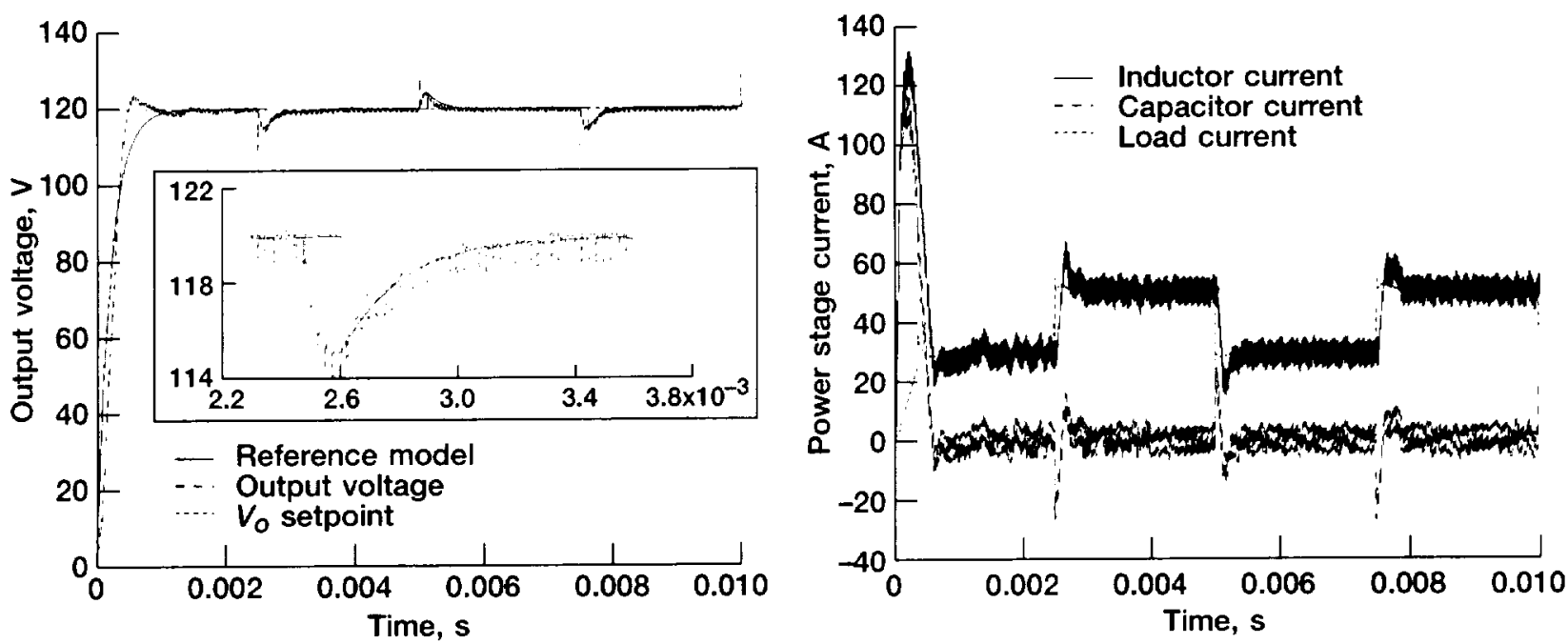

Figure 9.-FMRLC CMC response with $3.5-\mathrm{kW}$ and $6-\mathrm{kW}$ load changes.

\begin{tabular}{|c|c|c|c|c|c|c|c|c|c|c|c|c|}
\hline \multirow{2}{*}{\multicolumn{2}{|c|}{$P_{i}^{j, k}$}} & \multicolumn{11}{|c|}{$c^{k}$} \\
\hline & & -5 & -4 & -3 & -2 & -1 & 0 & +1 & +2 & +3 & +4 & +5 \\
\hline \multirow{11}{*}{$E^{\prime}$} & -5 & 0.000 & 0.000 & 0.000 & 0.000 & 0.000 & 0.000 & 0.000 & 0.000 & 0.000 & 0.000 & 0.000 \\
\hline & -4 & 0.000 & 0.000 & 0.000 & 0.000 & 0.000 & 0.000 & 0.000 & 0.000 & 0.000 & 0.000 & 0.000 \\
\hline & -3 & 0.000 & 0.000 & 0.000 & -0.535 & -1.000 & -1.000 & -1.000 & -0.392 & 0.000 & 0.000 & $-0.2000^{0}$ \\
\hline & -2 & -0.200 & 0.000 & -1.000 & -1.000 & -1.000 & -1.000 & $36^{-1.000_{35}}$ & $-1.000^{0}$ & 0.000 & 0.000 & $-1.000^{0}$ \\
\hline & -1 & -1.000 & -1.000 & -1.000 & -1.000 & -1.000 & -0.330 & 0.352 & $-1.000^{0}$ & $-0.0388^{0}$ & 0.000 & $-1.000^{0}$ \\
\hline & 0 & -1.000 & -1.000 & -1.000 & -1.000 & -1.000 & -0.311 & 0.677 & $1.000^{-5}$ & 1.000 & $0.054{ }^{1}$ & $-1.000^{1}$ \\
\hline & +1 & -1.000 & -1.000 & $-1.000^{0}$ & -0.316 & -1.000 & -0.171 & 0.677 & 1.000 & 1.000 & 1.000 & -0.167 \\
\hline & +2 & $-1.000^{0}$ & -0.400 & $-0.3544^{0}$ & 0.046 & 1.000 & 1.000 & 1.000 & 1.000 & 1.000 & 1.000 & 1.000 \\
\hline & +3 & 0.200 & 0.000 & 0.000 & 0.131 & 0.389 & 1.000 & 1.000 & 1.000 & 1.000 & 1.000 & 1.000 \\
\hline & +4 & 1.000 & 0.400 & 0.700 & 0.431 & 0.584 & 1.000 & 0.985 & 1.000 & 0.762 & 0.272 & 1.000 \\
\hline & +5 & $1.0000^{0}$ & 0.400 & 0.814 & 0.414 & 0.357 & 0.870 & 0.255 & 0.000 & 0.000 & 0.000 & 1.000 \\
\hline
\end{tabular}

Figure 10.-Learned knowledge base and modified elements (in boxes) used for fuzzy control knowledge base.

order to achieve a damped response. The reference model chosen for this controller is a first-order type with the transfer function

$$
G_{r}=\frac{\omega_{r}}{s+\omega_{r}}
$$

The value of $\omega_{r}$ was chosen to approximate the natural frequency of the converter to an open-loop step response. The gains of the FMRLC per the tuning guidelines ${ }^{9-10}$ have been selected with the following values:

$$
\left[g_{e} g_{c} g_{v}, g_{v_{i}} g_{u} g_{f} k_{i} \omega_{r}\right]=\left[\begin{array}{lll}
0.012 \times 10^{-7} & 4.3 \times 10^{-4} 8 \times 10^{-4}
\end{array}\right.
$$

12012030004714

The FMRLC controller knowledge base was initialized with zeros as its elements, indicating no knowledge of how to control the process initially. The resulting controller knowledge base from the learned control law, which was derived from the step response simulation (Fig. 9), is shown in Fig. 10. This figure also shows, in boxes, the elements modified and the modified values. outside the boxes, to be used as the knowledge base for the straight fuzzy controller (i.e., with the learning mechanism disabled). The modifications are primarily in the region associated with sign reversal of the controlled variable because of the undamped inductor current response. Some values other than zero are allowed near the center region of the knowledge base. where the tendency for sign reversal is not too drastic. This allowance was made to achieve a relatively faster response at the region of the knowledge base that becomes active near steady-state operation of the process.

As mentioned before, the FMRLC controller can be used for the final control of the process. in fact it shows very good response to step load changes. However, if smallsignal analysis is desired. the learning controller is not suitable because the controller nonlinearity is nonstationary. 


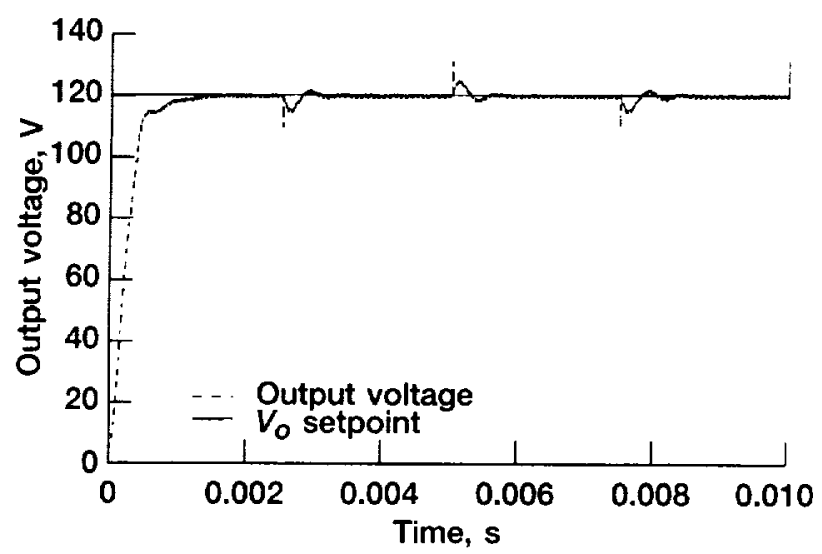

Figure 11.-Fuzzy CMC response with $3.5-\mathrm{kW}$ and 6-kW load changes.

\subsection{Fuzzy Current-Mode Control}

The conventional fuzzy controller has been implemented here for CMC by disabling the learning mechanism in Fig. 7. The control knowledge base learned from applying the FMRLC CMC (Fig. 10 with indicated modifications) was used for the fuzzy CMC controller. Figure 11 shows step responses of the conventional fuzzy CMC system.

\section{Stability Analysis of Fuzzy Current-Mode Control}

Various nonlinear stability analysis methodologies could be applied for analyzing fuzzy control systems. Some are the Lyapunov's indirect method, the circle criterion approach, and describing function analysis (DFA). ${ }^{11}$ The stability analysis covered in this section is based on the DFA approach supplemented with Bode analysis.

\subsection{Describing Function Analysis}

First, some background will be presented in computing the describing function. For an input $e(t)=C \sin (\omega t)$ to the nonlinear fuzzy controller there will be a periodic output $u(t)$. Expanding $u(t)$ into a Fourier series results in

$$
u(t)=\frac{a_{o}}{2}+\sum_{n=1}^{\infty}\left[a_{n} \cos (n \omega t)+b_{n} \sin (n \omega t)\right]
$$

The Fourier coefficients $a_{i}$ and $b_{i}$ are functions of $C$ and $\omega$ and are determined by

$$
\begin{gathered}
a_{o}=\frac{1}{\pi} \int_{-\pi}^{\pi} u(t) d(\omega t) \\
a_{n}=\frac{1}{\pi} \int_{-\pi}^{\pi} u(t) \cos (n \omega t) d(\omega t) \\
b_{n}=\frac{1}{\pi} \int_{-\pi}^{\pi} u(t) \sin (n \omega t) d(\omega t)
\end{gathered}
$$

Assuming that the fundamental component $u_{1}(t)$ is dominant (i.e., $a_{o}$ and the higher order harmonics can be neglected), then

$$
\begin{aligned}
u(t) \approx u_{1}(t) & =a_{1} \cos (\omega t)+b_{1} \sin (\omega t) \\
& =M(C, \omega) \sin [\omega t+\phi(C, \omega)]
\end{aligned}
$$

where

$$
M(C, \omega)=\sqrt{a_{1}^{2}+b_{1}^{2}}, \phi(C, \omega)=\arctan \left(\frac{a_{1}}{b_{1}}\right)
$$

Equation (19) can be written in complex form as

$$
u_{1}=M(C, \omega) e^{j[\omega t+\phi(C, \omega)]}=\left(b_{1}+j a_{1}\right) e^{j \omega t}
$$

The describing function of the nonlinear fuzzy controller is defined to be the complex ratio of the fundamental component representing the controller nonlinearity to the input sinusoid

$$
\begin{aligned}
N(C, \omega)=\frac{u_{1}}{C \sin (\omega t)} & =\frac{M(C, \omega) e^{j[\omega t+\phi(C, \omega)]}}{C e^{j \omega t}} \\
& =\frac{1}{C}\left(b_{1}+j a_{1}\right)
\end{aligned}
$$

Therefore, the nonlinear controller can be treated as if it were a linear element in a closed-loop control system consisting of the controller $N(C, \omega)$ and the process $G(j \omega)$ represented by Eq. (13). The harmonic balance equation of this closed-loop control system is

$$
G(j \omega) N(C, \omega)+1=0
$$

This equation can also be written as

$$
G(j \omega)=-\frac{1}{N(C, \omega)}
$$

If the closed-loop system has any limit cycles, its amplitude and frequency can be predicted by solving Eq. (23). If there are no solutions, there are no harmonic oscillations. However, solving Eq. (23) can be quite complex. especially for higher order systems, and it is best to solve this equation graphically by plotting $-1 / N(C, \omega)$ against $G(j \omega)$ and finding its intersection points. For an oscillation to exist the intersection must occur at the same frequency $\omega$. The values $C$ and $\omega$, at this intersection point, are the amplitude and frequency of the harmonic oscillation. If points near the intersection and along the increasing $C$ side of the curve $-1 / N(C, \omega)$ are not encircled by the curve $G(j \omega)$, the corresponding limit cycle is stable. Otherwise, the limit cycle is unstable.

For experimental evaluation of the fuzzy controller describing function, first the fuzzy controller will be excited with sinusoidal frequency sweeps of different amplitudes to compute the control output $u(t)$. The input sinusoidal sweep function is constructed here as

$$
e(t)=C \sin \left(2 \pi \alpha f_{s} t\right)
$$


where

$$
\alpha=1+\frac{\left(f_{s}-f_{f}\right)}{f_{s}} \frac{t}{t_{e}}
$$

and $f_{s^{*}}, f_{f}$, and $t_{c}$ are the starting frequency of the sinusoidal sweep, the final frequency, and the simulation time. respectively. The minimum sweep frequency is chosen to be at least a decade below the expected crossover frequency of the closed-loop gain, and the maximum sweep frequency is chosen to be equal to the subharmonic frequency (i.e.. half the switching frequency). After the control outputs are computed for different values of $C$, FFT" $s$ are used to compute transfer function estimates of Eq. (21) as

$$
N(C, \omega)=\frac{P_{e u}(C, \omega)}{P_{e e}(C, \omega)}
$$

where $P_{e u}$ and $P_{e e}$ are the cross spectrum of $e$ and $u$ and the power spectrum of $e$, respectively.

Figure 12 shows the transfer function estimates for different amplitude sweeps. MATLAB was used to compute these transfer functions in Eq. (25). These transfer functions were approximated with poles and zeros by drawing the corresponding straight-line asymptotes. A slope transition of the transfer function indicates first- or second-order zeros or poles depending on the direction and order of the transition. The damping of the secondorder responses is a measure of the sharpness of the response transition. Occasionally, final adjustments need to be performed to match the phase responses of Eq. (25). not shown here. On this basis the transfer function approximations for the responses of Eq. (25), displayed in Fig. 12, are of the form

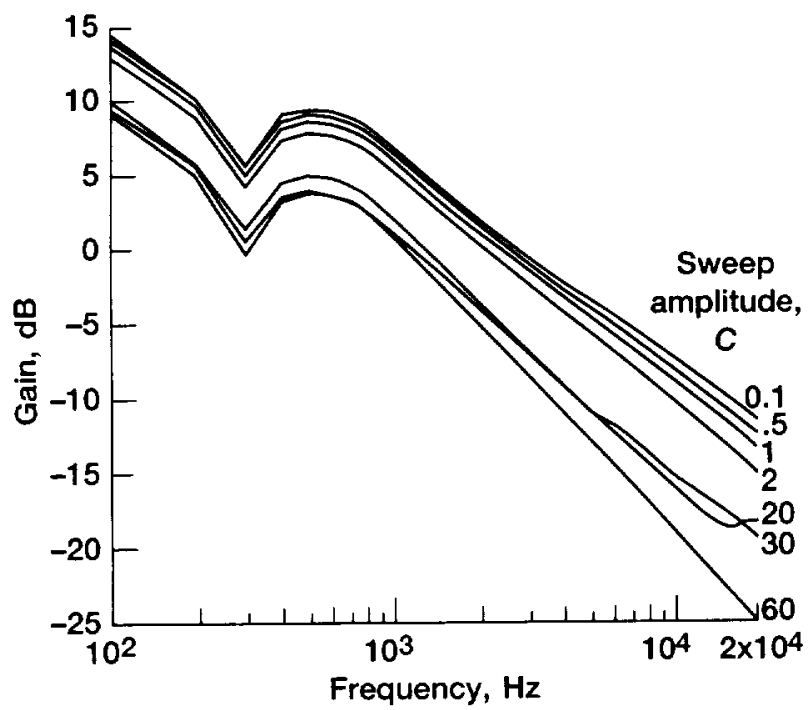

Figure 12.-Transfer functions of fuzzy controller constructed using sine sweeps with different amplitudes and FFT's.

$$
N_{a}(C, s)=K \frac{P_{a n}(C, s)}{P_{a d}(C, s)}
$$

where $P_{a n}(C . s)$ and $P_{a d}(C . s)$ are the approximation polynomials of the numerator and denominator. respectively. All the polynomials, as a function of the sweep amplitude $C$, are found to have the same general characteristic as

$$
\begin{aligned}
& P_{a n}(s)=\left(\frac{s^{2}}{\omega_{z 1}^{2}}+\frac{2 \zeta_{z-1} s}{\omega_{z 1}}+1\right)\left(\frac{s}{\omega_{z 2}}+1\right)\left(\frac{s}{\omega_{z-3}}+1\right)\left(\frac{s}{\omega_{z-4}}+1\right) \\
& P_{a d}(s)=s\left(\frac{s^{2}}{\omega_{p 1}^{2}}+\frac{2 \zeta_{p 1} s}{\omega_{p 1}}+1\right)\left(\frac{s^{2}}{\omega_{p 2}^{2}}+\frac{2 \zeta_{p 2} s}{\omega_{p 2}}+1\right)\left(\frac{s}{\omega_{p 3}}+1\right)
\end{aligned}
$$

Figure 13 shows a frequency response based on FFT's (Eq. (25)) and its approximation (Eq. (26)) for $C=$ 2.0. The approximations have less accuracy at low frequencies. However, the low-frequency response will have little influence approximately one frequency decade above, where the main interest of the response lies (i.e., at the neighborhood of the crossover frequency), as will be seen later. For the transfer function approximations shown in Fig. 14 corresponding to Eq. (26) the parameters of the transfer functions are

$$
\begin{aligned}
& {\left[\boldsymbol{C K} f_{z 1} f_{-2} f_{z 3} f_{-4} f_{p 1} f_{p 2} f_{p 3} \zeta_{-1} \zeta_{p 1} \zeta_{p 2}\right]=} \\
& {\left[\begin{array}{lllllllllllll}
0.1 & 3000 & 325 & 450 & 720 & 1770 & 375 & 850 & 6000 & .29 & .28 & .57 \\
2.0 & 3000 & 325 & 450 & 720 & 1770 & 375 & 850 & 4900 & .29 & .32 & .60 \\
20 . & 2000 & 325 & 450 & 720 & 1770 & 375 & 850 & 3000 & .25 & .29 & .60 \\
60 . & 1500 & 32.5 & 450 & 720 & 1770 & 375 & 850 & 3000 & .29 & .26 & .54
\end{array}\right]}
\end{aligned}
$$

As discussed before, Eq. (23) is solved graphically by plotting its Nyquist. Fig. 15, of $G(j \omega)$ represented by Eq. (13) and $-1 / N(C, \omega)$, where $N(C, \omega)$ is represented by

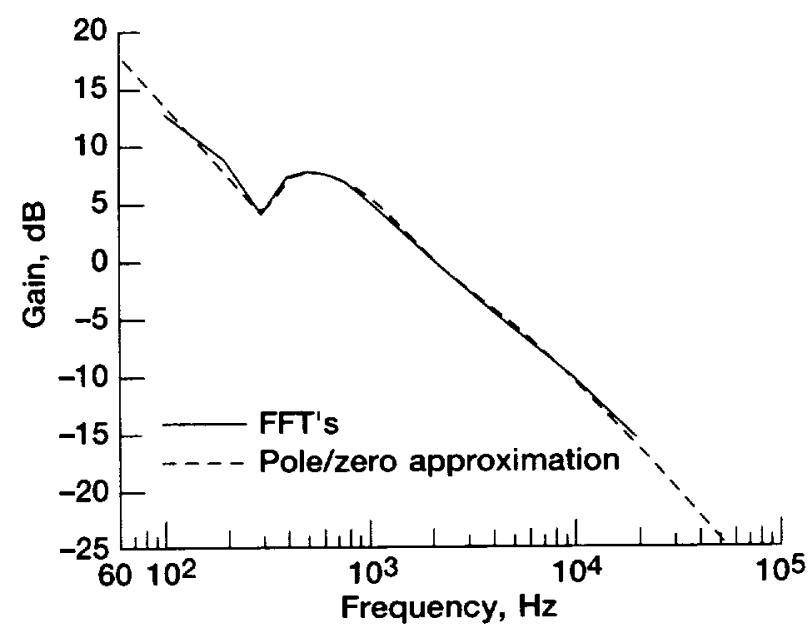

Figure 13.-Fuzzy controller transfer function and its pole-zero transfer function approximation. 


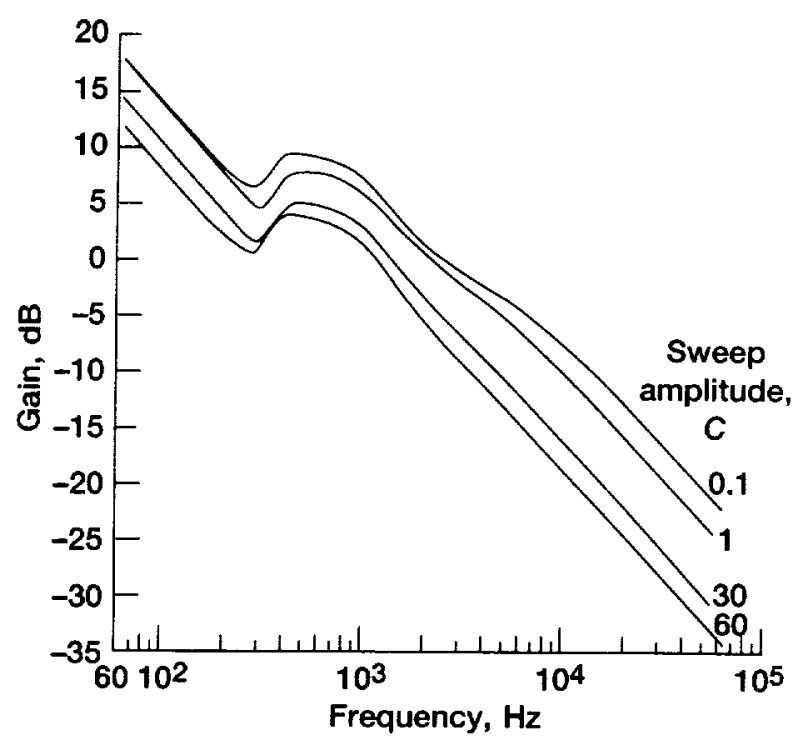

Figure 14.-Approximated transfer functions of fuzzy controller by applying sinusoidal sweeps of different amplitudes.

Eq. (26). The $G(j \omega)$ of Eq. (13) is plotted at two different operating points of the converter power stage (i.e., at $100 \%$ load and at approximately $10 \%$ load, which represents the borderline between CCM and DCM). The fact that the plot $G(j \omega)$ passes very near the -1 point on the Nyquist plot is an indication that the open-loop gain of the power stage is nearly unstable without proper compensation. Besides the power level operating points, the input line voltage constitutes operating point changes that will also influence $G(j \omega)$. If desirable, an analysis for changes in line voltages can also be carried out in the exact same way, but this analysis is beyond the scope of this paper.

As shown in Fig. 15 there are several intersection points. However, a closer examination of the complex vectors of these transfer functions as a function of $\omega$ reveals that none of these intersections occurs at the same $\omega$, which is the condition for predicting sustained harmonic oscillations or instability. The closest these transfer functions came to intersecting for the same $\omega$ was for the $C=60$ plot, as was expected from the Bode analysis that follows. The time domain response shown in Fig. 11 confirms the prediction of the describing function analysis (i.e., the absence of sustained system limit cycles).

\subsection{Bode Analysis}

4.2.1 Closed-loop gain.-Bode analysis allows for a convenient way to carry out direct quantifiable measurements of the system's stability margins. In a closed-loop control system consisting of a controller with a transfer function $N(s)$ and a process with a transfer function $G(s)$, the closed-loop gain of the system is

$$
L_{c l}(s)=G(s) N(s)
$$

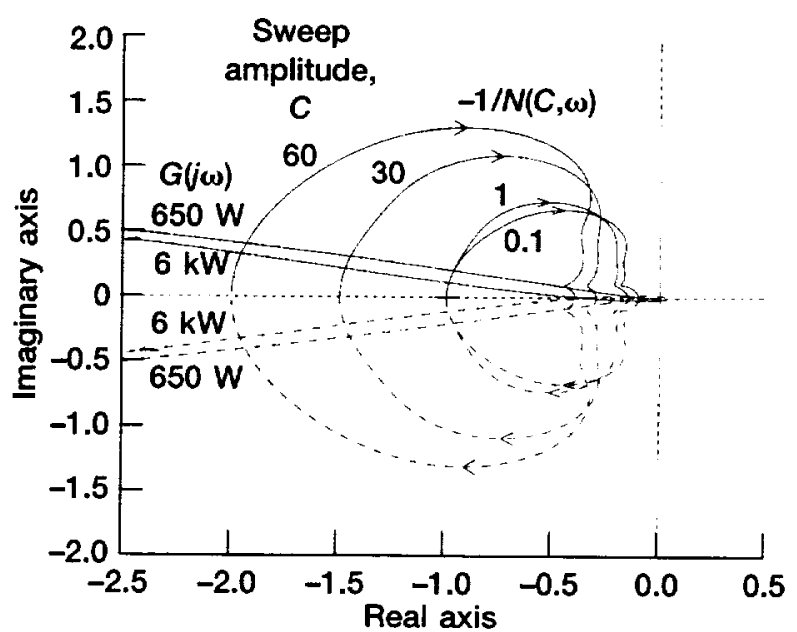

Figure 15.-Nyquist plot of $G(j \omega)$ at $6 \mathrm{~kW}$ and $650 \mathrm{~W}$ versus $-1 / N(C, \omega)$.

The overall input-to-output transfer function of the closedloop system will have the characteristic equation of $G(s) N(s)+1=0$, the same as Eq. (23). From this characteristic equation it is observed that when $L_{c l}=-1$, or in phasor terms $L_{c l}=0 \mathrm{~dB}\left\langle 180^{\circ}\right.$, the characteristic equation and therefore the overall closed-loop transfer function will have a zero denominator. Therefore, the system will be unstable for $L_{c l}=-1$. The difference, between the actual phase angle of $L_{c l}$ and $180^{\circ}$ at the point where $L_{c l}$ crosses $0 \mathrm{~dB}$, is defined as the system stability phase margin. Similarly, the gain margin of the system is defined to be the difference between $0 \mathrm{~dB}$ and the actual magnitude of $L_{c l}$ when the phase of $L_{c l}$ crosses $180^{\circ}$. When the system phase and/or gain margins are relatively small, the system will normally exhibit an oscillatory response, similar to an underdamped response with increased sensitivity.

Figures 16 and 17 show the closed-loop gain responses, based on the converter transfer function (Eq. (13)) and the fuzzy controller transfer function (Eq. (26)), at $100 \%$ power and at the borderline between CCM and DCM, respectively. In both Figs. 16 and 17 the converter has less phase margin for larger values of $C$. For instance, for $C=60$ the phase margins are $\sim 9^{\circ}$ and $\sim 5^{\circ}$, respectively, for loads of $6 \mathrm{~kW}$ and $650 \mathrm{~W}$. At low values of $C$ the corresponding phase margins for high and low power levels are $\sim 36^{\circ}$ and $\sim 20^{\circ}$, respectively. Theoretically, the gain margins are infinite in all cases, since the phases do not cross the $180^{\circ}$ line. However, there is another measure of stability, conditional stability, which in brief is a measure of how close the phase approaches $180^{\circ}$ while the magnitude approaches $0 \mathrm{~dB}$. Not shown here, the phase margins can be improved by adjusting the values of the membership functions (Fig. 10 at the center region of the knowledge base) to move them closer to the origin. This 

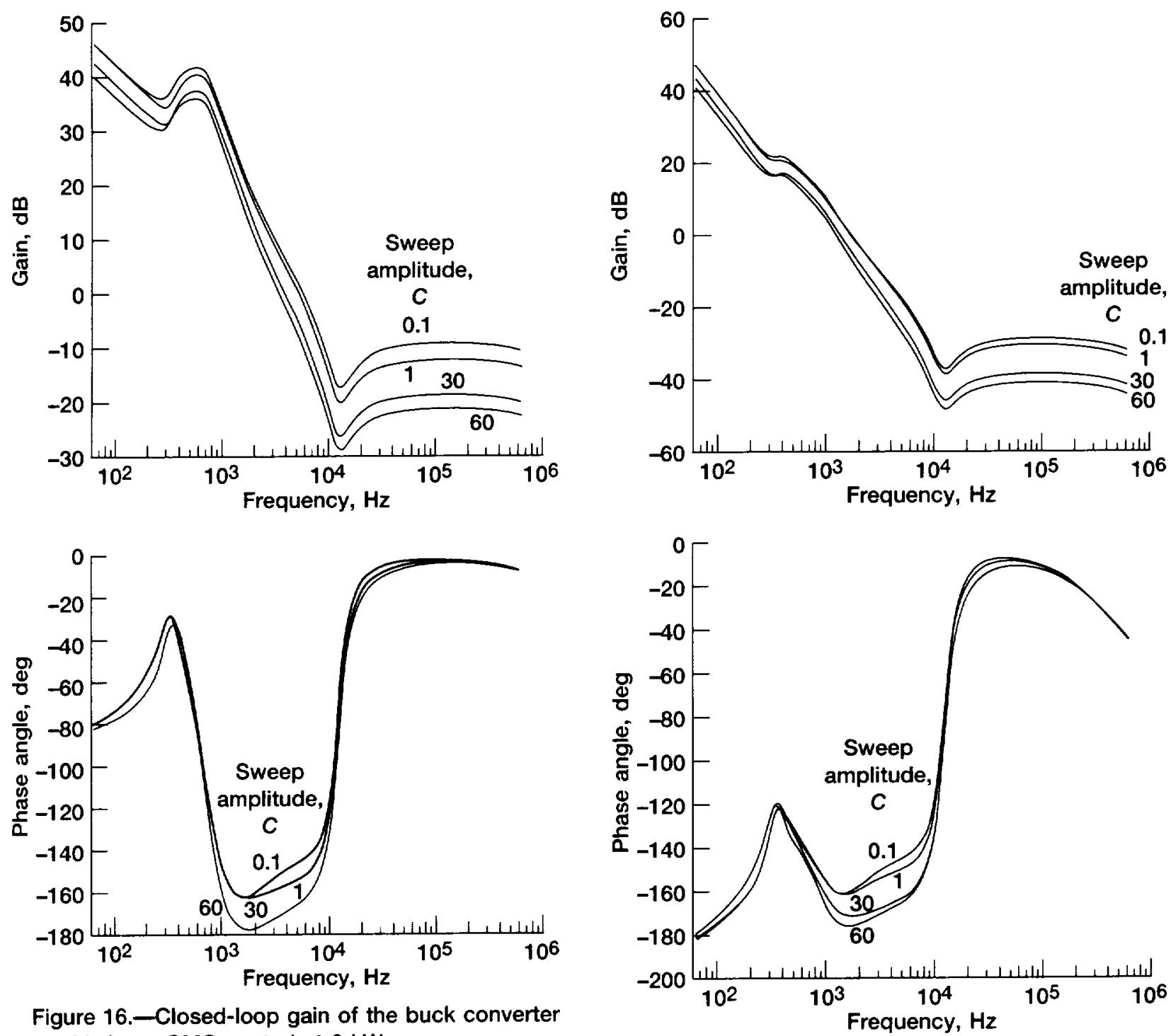

Figure 16.-Closed-loop gain of the buck converter with fuzzy $\mathrm{CMC}$ control at $6 \mathrm{~kW}$.

will make the response more damped, but slower, with a little more overshoot. Of course, improving the filter design, which was purposely underdamped, is another way to improve the stability margins.

4.2.2 Output impedance.-Another important measure of system performance is the converter output impedance. A source supplying a single or an aggregate load, as a system, will be subjected to additional stability criteria at the source-load interface as

$$
G_{t}(s)=G_{s}(s) G_{l}(s) /\left[1+\frac{Z_{o}(s)}{Z_{l}(s)}\right]
$$

where $G_{r}(s), G_{s}(s)$, and $G_{l}(s)$ are the input-to-output transfer functions of the overall system, the source, and the load, respectively; $Z_{o}(s)$ is the source output impedance; and $Z_{l}(s)$ is the load input impedance. For the power converter in Fig. 1 its open-loop output impedance, which is the

Figure 17.-Closed-loop gain of the buck converter with fuzzy CMC control at bordenline of CCM and DCM ( 650 W).

source impedance of the output filter, including the inductor effective series resistance $R_{\text {in }}$, is

$$
Z_{P}(s)=R_{\mathrm{in}} \frac{\left(C_{f} L_{c} s^{2}+R_{c} C_{f} s+1\right)\left(\frac{L_{f}}{R_{\mathrm{in}}} s+1\right)}{C_{f} L_{f} s^{2}+C_{f} R_{c} s+1}
$$

for $L_{f}$ " $L_{c}$ and $R_{c} " R_{\text {in }}$. The closed-loop output impedance is

$$
Z_{o}(s)=\frac{Z_{p}(s)}{1+L_{c l}(s)}
$$

where $Z_{p}(s)$ is the open-loop output impedance (i.e., $\left.Z_{p}=\left.\frac{\hat{v}_{o}}{\hat{i}_{o}}\right|_{\hat{d}=0}\right)$. 

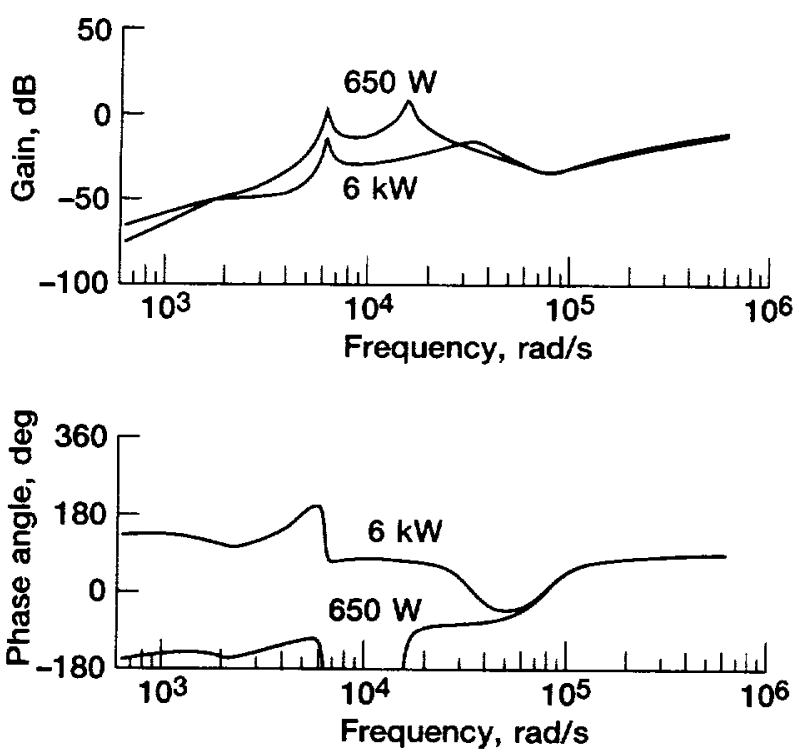

Figure 18.-Closed-loop output impedance of buck converter with fuzzy CMC control at $C=1.0$.

Figure 18 shows the closed-loop output impedance of the converter at power levels of $6 \mathrm{~kW}$ and $650 \mathrm{~W}$ and for $C=1$, with a parasitic value of $R_{\text {in }}$. The phase of the impedances in Fig. 18 needed to be unramped. A complete analysis will include the output impedance at different values of $C$ and an actual load impedance. to study the stability margins of the system. For such an analysis the phase margin, measured at the intersecting points of the two impedances and based on Eq. (28), will be computed as the addition of the load impedance phase minus the source impedance phase subtracted from $180^{\circ}$. The output impedance can also be improved by redesigning the output filter.

\section{Concluding Remarks}

In this paper fuzzy control was applied to traditional current-mode control (CMC) by replacing the typical lead-lag compensation design. It was demonstrated that, with proper design of the Fuzzy Model Reference Learning Control (FMRLC), very good time responses to load step changes can be obtained even with a highly undamped power converter design. The control knowledge base learned with the FMRLC was used to develop a straight fuzzy controller for the converter in order to conduct small-signal analysis. The paper demonstrated the ability to conduct small-signal analysis of the converter with fuzzy control by developing a small-signal model of the fuzzy controller using sinusoidal sweeps and fast Fourier transforms. The small-signal analyses conducted by employing the describing function and Bode analysis showed the feasibility of applying fuzzy control to CMC, while still employing powerful traditional analysis tools.

\section{$\underline{\text { References }}$}

1. Mamdani,E.H.: Application of Fuzzy Algorithms for Simple Dynamic Plant. Proceedings of the Institution of Electrical Engineers, vol. 121, no. 12. 1974, pp. 1585-1588.

2. Procyk, T.J.; and Mamdani, E.H.: Linguistic SelfOrganizing Process Controller. Automatica, vol. 15, no. 1, 1979, pp. 15-30.

3. Zadeh, L.A.: Communication: Fuzzy Algorithms. Informat. Control, vol. 12, no. 2, 1968, pp. 94-102.

4. Zadeh, L.A.: Outline of a New Approach to the Analysis of Complex Systems and Decision Process. IEEE Trans. Man Cybern., vol. SMC-3, 1973, pp. 28-44.

5. Layne, J.R.; and Passino, K.M.: Fuzzy Model Reference Learning Control. Proceedings of the IEEE Conference on Control Applications, Institute of Electrical and Electronics Engineers, New York, NY, 1992, pp. 686-691.

6. Middlebrook, R.D.; and Cuk, S.: A Generalized Uniform Approach To Modeling SwitchingConverter Power Stages. Proceedings of the IEEE Power Electronics Specialist Conference, The Society, New York, NY, 1976, pp. 18-34.

7. Middlebrook, R.D.: Topics in Multiple-Loop Regulators and Current-Mode Programming. Proceedings of the IEEE Power Electronics Specialist Conference. New York, NY, 1985, pp. 716-732.

8. Ridley, R.B.: A New, Continuous-Time Model for Current-Mode Control. Modeling. Analysis, and Design of PWM Converters, Virginia Power Electronics Center, Blacksburg, VA, 1989. pp. 321-332.

9. Kopasakis, G.: Adaptive Performance Seeking Control Using Fuzzy Model Reference Learning Control and Positive Gradient Control. AIAA Paper 97-3191, 1997.

10. Kopasakis, G.: Nonlinear Performance Seeking Control Using Fuzzy Model Reference Learning Control and the Method of Steepest Descent. AIAA Paper 97-3362, 1997.

11. Passino, K.M.; and Yurkovich, S.: Fuzzy Control. Addison-Wesley, Menlo Park, CA, 1998. 



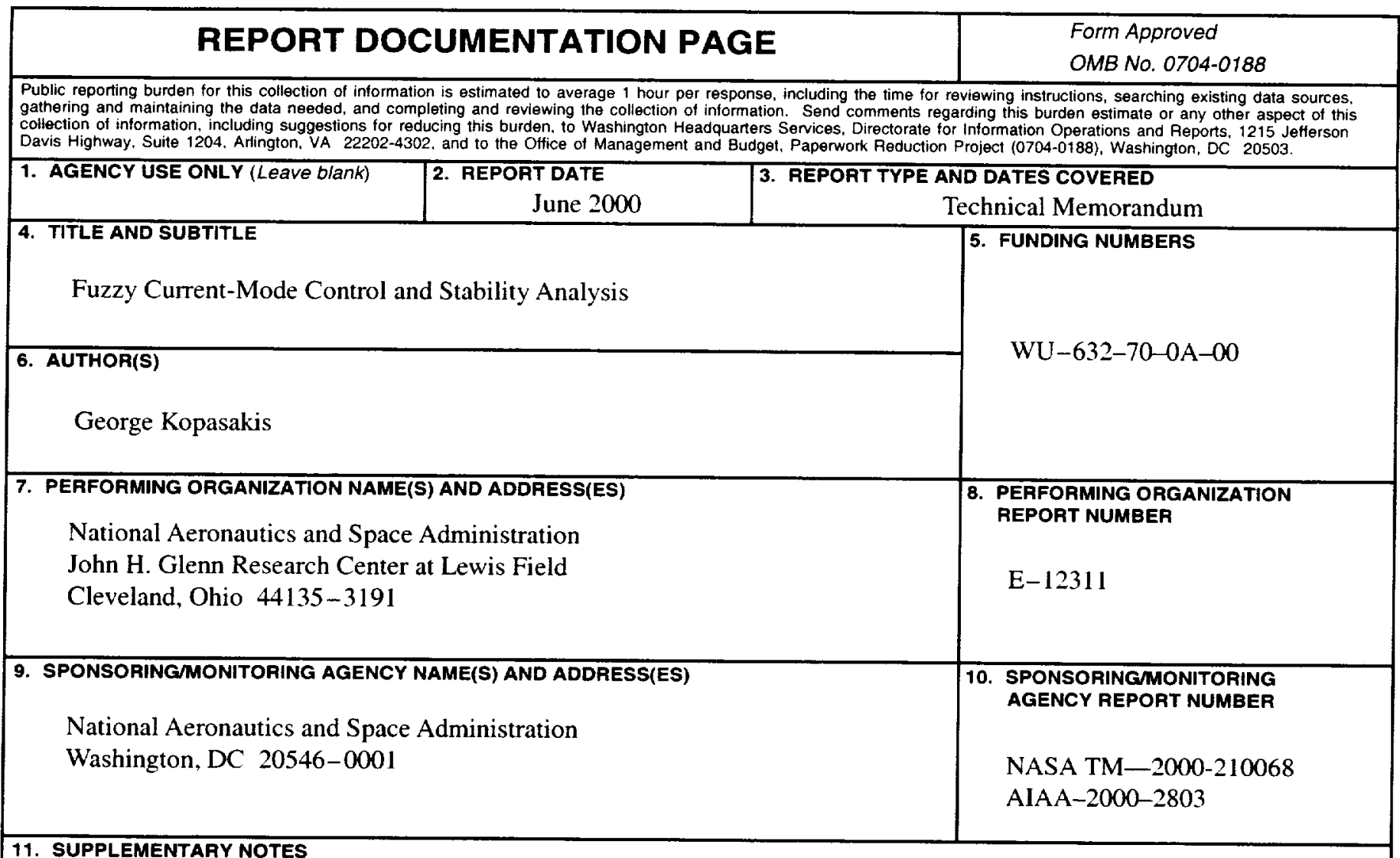

Prepared for the 35th Intersociety Energy Conversion Engineering Conference sponsored by the American Institute of Aeronautics and Astronautics, Las Vegas, Nevada, July 24-28, 2000. Responsible person, George Kopasakis, organization code 5440, (216) 433-5327.

12a. DISTRIBUTION/AVAILABILITY STATEMENT

Unclassified - Unlimited

Subject Category: 33

Distribution: Nonstandard

This publication is available from the NASA Center for AeroSpace Information. (301) 621-0390.

13. ABSTRACT (Maximum 200 words)

In this paper a current-mode control (CMC) methodology is developed for a buck converter by using a fuzzy logic controller. Conventional CMC methodologies are based on lead-lag compensation with voltage and inductor current feedback. In this paper the converter lead-lag compensation will be substituted with a fuzzy controller. A small-signal model of the fuzzy controller will also be developed in order to examine the stability properties of this buck converter control system. The paper develops an analytical approach, introducing fuzzy control into the area of CMC.

\section{SUBJECT TERMS}

Current mode control; Converter control; Fuzzy control; Fuzzy learning control; Learning control; Converter stability; Converter stability analysis; Fuzzy logic

\begin{tabular}{|c|c|}
\hline $\begin{array}{c}\text { 17. SECURITY CLASSIFICATION } \\
\text { OF REPORT } \\
\text { Unclassified }\end{array}$ & $\begin{array}{c}\text { 18. SECURITY CLASSIFICATION } \\
\text { OF THIS PAGE } \\
\text { Unclassified }\end{array}$ \\
\hline
\end{tabular}

19. SECURITY CLASSIFICATION
OF ABSTRACT
Unclassified

NSN 7540-01-280-5500
15. NUMBER OF PAGES

16

16. PRICE CODE $\mathrm{A03}$

20. LIMITATION OF ABSTRACT 
